\title{
Development of High Thermal Stability Geopolymer Composites Enhanced by Nano Metakaolin
}

\author{
El Nagar AM*, Khater HM \\ Housing and Building National Research Centre (HBRC), 87 El-Tahrir St, Dokki, Giza, P.O. Box 1770 Cairo, \\ Egypt \\ * Corresponding Author: abdeenelnagar@yahoo.com
}

Received: 01-10-2018

Accepted: 04-02-2019

\begin{abstract}
This paper deals with study of thermal stability of geopolymer composites enhanced by nano metakaolin materials (NMK) and exposed to high firing temperature up to $1000{ }^{\circ} \mathrm{C}$. The main geopolymer made up of water cooled slag having various kaolin ratios. The activators used are $\mathrm{Na}_{2} \mathrm{SiO}_{3}$ and $\mathrm{NaOH}$ in the ratio of 3:3. The thermo-physical, microstructural and mechanical properties of the geopolymers before and after the exposure to elevated temperatures of $300,500,600800$ and $1000{ }^{\circ} \mathrm{C}$ have been investigated. The fire shrinkage of the geopolymer specimens increased by increasing temperature up to $1000{ }^{\circ} \mathrm{C}$. Also, the fire shrinkage increased slowly up to $500{ }^{\circ} \mathrm{C}$. The mechanical strength of geopolymer specimens increased with temperature up to $500{ }^{\circ} \mathrm{C}$. The good thermo-physical and mechanical properties for these geopolymer composites increase the possibility of vast application of these eco-friendly materials in construction sectors.
\end{abstract}

Key words: firing shrinkage, geopolymer composites, slag, kaolin, nano metakaolin.

\section{Introduction}

The geopolymerization technology introduced as an ideal and novel environmentally-friendly process for producing supplementary materials to ordinary Portland cement (OPC) in 1980s, by professor Joseph Davidovits that possessing higher mechanical and durability properties. The geopolymers synthesizing technology is based on the relatively simple alkaline activation of a source material which is rich in silicon (Si) and aluminum (Al) in amorphous form at relatively low temperature (Davidovits, 1999). Geopolymers have superior resistance to thermal shrinkage when exposed to temperatures up to $1000^{\circ} \mathrm{C}$ compared to Portland cements (Palomo et al., 1999; Duxson et al, 2005 ; Duxson et al., 2007; Rahier, 1996) very little attention has been given to the wider issue of ambient temperature drying shrinkage (Barbosa \& MacKenzie, 2003a). Unlike Portland cement, water is not incorporated directly into the geopolymer gel product. Only a small percentage of the mixing water remains as interstitial water in the geopolymer gel shrinkage (Barbosa \& MacKenzie, 2003-b). This fact, combined with the high water requirement to mix geopolymer pastes, means that there is a large excess of unbound or free water, which can evaporate from the hardened paste under low relative humidity conditions at ambient temperature (Rahier, 1996). Despite the lack of chemically bound water, it still plays an important role in structural stability. Excessive water loss under relatively normal environmental conditions can result in extensive shrinkage cracking of specimens (Barbosa \& MacKenzie, 2003-a). The previous studies that investigated thermal properties of fly ash materials possessed low thermal shrinkage and good strength maintenance after exposure to high temperatures (Bakharev, 2006; Kong \& Sanjayan, 2008; Kong \& Sanjayan, 2010; Rickard et al., 2010). The FA geopolymers in these papers were directly heated from room temperature up to the elevated temperature of $800^{\circ} \mathrm{C}$ or further up to $1200^{\circ} \mathrm{C}$, without studying the changes in the geopolymer phase composition and microstructure occurred at temperatures ranged from about $600-800^{\circ} \mathrm{C}$. Recently, these changes have been highlighted via dilatometric analysis 
(Rickard et al., 2012; Provis et al., 2009). However, these studies were focused substantially on the effect of the silicate phase concentration exist in the FAs sources and/or geopolymers which lacks to the micro-structural and mechanical analysis. Also, all the designed alkali activated fly ash based systems, not depending on initial curing condition, displayed a higher resistance to high temperature with respect to traditional cementitious binders, which are affected by very high strength loss at high temperature such as $800^{\circ} \mathrm{C}$ (Messina et al., 2018).

Adding nano silica have good effect and improve residual compressive strength of both sodium and potassium activators synthetized geopolymers at elevated temperatures. The potassium activator synthetized geopolymers containing nano silica exhibited higher residual compressive strength at elevated temperatures above $400{ }^{\circ} \mathrm{C}$ than its sodium based counterparts (Shaikh \& Haque, 2018).

The main objective of the current study is to address the thermo-physical, mechanical and the macro/micro-structural changes that the geopolymer products experience after exposing to different elevated temperatures of $300,500,600,800$ and $1000{ }^{\circ} \mathrm{C}$ to enhance the understanding about this new type of building materials.

\section{Geological setting of kaolin deposit}

The studied kaolin raw material was delivered from quarry of the Middle East Mining Company (MEMCO) (6 km west of Gebel Gunna in the central Sinai, Egypt). The kaolinitic sandstone beds in the quarry belong to the Naqus Formation of the Early Paleozoic age (El Nagar, 2016). These rocks are partially covered in some parts by windblown sands and some gravel. These loose sands and detrital materials belong to the recent age.

The studied quarry face section attains about $5.5 \mathrm{~m}$ thick (Fig. 1). The quarry bed is completely composed of kaolinitic sandstone; whitish, very fine grain, compact and hard. The Figure 1 illustrate the lithostratigraphic columnar section of the interface studied quarry of Naqus Formation, west of Gebel Gunna, Sinai, Egypt.

\begin{tabular}{|c|c|c|c|c|}
\hline Age & Formation & $\begin{array}{c}\text { Thick } \\
\text { m }\end{array}$ & Lithology & Lithologic discreption \\
\hline $\begin{array}{l}\text { The } \\
\text { Recent }\end{array}$ & & 0.50 & 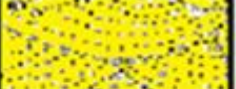 & Windblown sands white to brown sands \\
\hline 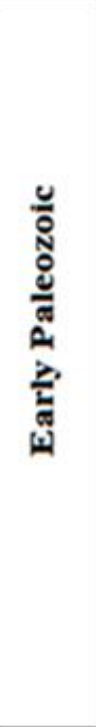 & 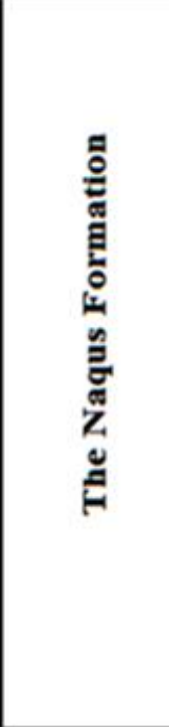 & 5.0 &  & $\begin{array}{l}\text { Kaolinitic sandstone; fine and } \\
\text { medium grains, yellowish white } \\
\text { and cemented by fine grained } \\
\text { kaolin, included lenses of } \\
\text { kaolin. } \star\end{array}$ \\
\hline
\end{tabular}

Fig. 1. Lithostratigraphic columnar section of the interface studied quarry of Naqus Formation, west of Gebel Gunna, Sinai. $\backslash$ Refers to the bed of samples collected. 


\section{Materials and Methods}

\subsection{Materials}

Materials used in this work are kaolin collected from Sinai, West of Gebel Gunna, Egypt; water cooled slag also called ground granulate blast furnace slag (GGBFS) sourced from Iron and Steel Factory- Helwan, Egypt. Commercially sodium hydroxide $(\mathrm{NaOH})$ with purity $98 \%$ in the form of pellets and sodium silicate $\left(\mathrm{Na}_{2} \mathrm{SiO}_{3}\right)$ are used as alkali activators. Nano-metakaolin Particles were prepared in the lab from the kaolin raw by firing at $800^{\circ} \mathrm{C}$ for $2 \mathrm{hr}$ with heating rate of $5{ }^{\circ} \mathrm{C}$ /min. The chemical composition of the starting raw materials are tabulated in Table (1). Also, the used dose of NMK was chosen at 3\% from total weight based on the literatures (El Nagar, 2016).

Table 1. Chemical composition of the used raw materials (mass).

\begin{tabular}{|c|c|c|c|}
\hline Material & Kaolin & $\begin{array}{c}\text { Nano } \\
\text { meta- } \\
\text { kaolin }\end{array}$ & GGBFS \\
\hline \hline $\mathrm{SiO}_{2}$ & 49.86 & 56.14 & 36.59 \\
\hline $\mathrm{Al}_{2} \mathrm{O}_{3}$ & 34.10 & 38.21 & 10.01 \\
\hline $\mathrm{Fe}_{2} \mathrm{O}_{3}$ & 0.30 & 0.38 & 1.48 \\
\hline $\mathrm{CaO}$ & 0.09 & 0.07 & 33.07 \\
\hline $\mathrm{MgO}^{\mathrm{SO}}{ }_{3}$ & 0.26 & 0.37 & 6.53 \\
\hline $\mathrm{K}_{2} \mathrm{O}$ & 0.59 & 0.18 & 3.52 \\
\hline $\mathrm{Na}_{2} \mathrm{O}$ & 0.02 & 0.00 & 0.74 \\
\hline $\mathrm{TiO}_{2}$ & 0.88 & 0.02 & 1.39 \\
\hline $\mathrm{MnO}_{2}$ & 0.01 & 0.00 & 0.52 \\
\hline $\mathrm{P}_{2} \mathrm{O}_{5}$ & 0.35 & 0.26 & 0.10 \\
\hline $\mathrm{Cl}$ & 0.00 & 0.00 & 0.05 \\
\hline $\mathrm{LOI}$ & 13.44 & 3.13 & 0.00 \\
\hline $\mathrm{Total}^{-}$ & 99.92 & 99.89 & 99.69 \\
\hline $\mathrm{Notes}$ & & & $\mathrm{BaO}=5.00$ \\
\hline
\end{tabular}

\subsection{Experimental}

\subsubsection{Preparation of activator solution}

The alkaline solution was prepared by dissolving $\mathrm{NaOH}$ pellets in water and then added to the required amount of water glass. After the solution was cooled down, the nano-kaolin powder was stirred for 15 minutes. The binders were first dry mixed together. Then, the prepared activator solution was added on the powder and mixed for 5 minutes.

\subsubsection{Casting and molding}

The mix was poured in steal molds of $2.5 \mathrm{~cm}$ side length cube and vibrated for 30 second using a vibrating table. All mixes were left to cure at ambient temperature for 24 hours, and then subjected to curing temperature of $38{ }^{\circ} \mathrm{C}$ and $100 \%$ relative humidity in a controlled humidity chamber. Compressive strength was measured at 28 days before firing. Compressive strength tests were carried out using five tones German Brüf pressing machine with a loading rate of 100 $\mathrm{kg} / \mathrm{min}$ determined according to ASTM-C109-07 (2012), as follows:

$$
\mathbf{C}=\mathbf{W} / \mathbf{A}
$$

Where, $\mathrm{C}=$ Compressive strength of the specimen, $\mathrm{kg} / \mathrm{cm}^{2} . \mathrm{W}=$ Total load at which failure occurs, kg. $A=$ Calculated area of the bearing surface, $\mathrm{cm}^{2}$. 
As a confirmatory tool, thermo-gravimetric (TGA) analysis was used. The thermal analyses were carried out using computerized DT-50 thermal analyzer (Shimadzu Co., Kyoto, Japan). The heating rate was $20^{\circ} \mathrm{C} / \mathrm{min}$. The heating temperature was up to $1000^{\circ} \mathrm{C}$ for TGA under nitrogen atmosphere $(30 \mathrm{ml} / \mathrm{min})$. The microstructure of specimens was studied using SEM Inspect $\mathrm{S}$ (FEI Company, Netherland). The studied mixes composition shown in Table (2).

Table 2. The studied mix design of geopolymer composites specimens.

\begin{tabular}{|c|c|c|c|c|c|}
\hline Mix & Kaolin, $\%$ & Slag, $\%$ & $\mathrm{NMK}, \%$ & $\mathrm{NaOH}, \%$ & $\mathrm{Na}_{2} \mathrm{SiO}_{3}, \%$ \\
\hline \hline G1 & 50 & 50 & 3 & 3 & 3 \\
\hline G2 & 20 & 80 & 3 & 3 & 3 \\
\hline G3 & - & 100 & 3 & 3 & 3 \\
\hline
\end{tabular}

\subsection{Fire shrinkage}

At the age of 28 days, the geopolymer specimens were dried at $105^{\circ} \mathrm{C}$ for $24 \mathrm{hrs}$, then fired at temperatures of $300{ }^{\circ} \mathrm{C}, 500{ }^{\circ} \mathrm{C}, 600{ }^{\circ} \mathrm{C}, 800{ }^{\circ} \mathrm{C}$ and $1000{ }^{\circ} \mathrm{C}$ for $2 \mathrm{hrs}$ with a heating rate of 5 ${ }^{\circ} \mathrm{C} / \mathrm{min}$. Afterwards, the geopolymer specimens were left to cool inside the furnace to room temperature. Then, fire shrinkage test for the fired specimens was measured according to the following equation.

Firing shrinkage $\%$ was calculated for each test specimen using the following formula Norsker, 1987):

\section{Average of Firing Shrinkage \% $=(D L-F L) / D^{*} 100$}

Where: DL means dried length and FL is fired length.

\section{Results and discussion}

\subsection{Firing shrinkage}

Fire shrinkage results of dried geopolymer specimens (G1, G2 and G3) fired at 300, 500, 600, 800 and $1000{ }^{\circ} \mathrm{C}$ are shown in (Table 3 ) and plotted against temperature degrees in Fig. (2).

It can be seen that the firing shrinkage increases for the geopolymer specimens with temperatures higher than $300^{\circ} \mathrm{C}$ and up to $1000^{\circ} \mathrm{C}$ is which can be related to water evaporation from the geopolymer structure in a phenomenal called the 'vapors effect' as discussed elsewhere (Abdulkareem et al., 2013).

Table 3. Fire shrinkage of dried geopolymer specimens fired at $300,500,600,800$ and $1000^{\circ} \mathrm{C}$.

\begin{tabular}{|c|c|c|c|}
\hline \multirow{2}{*}{$\begin{array}{c}\text { Tempertaure } \\
\text { degree }\end{array}{ }^{\circ} \mathrm{C}$} & \multicolumn{3}{|c|}{ Fire Shrinkage, \% } \\
\cline { 2 - 4 } & G1 & G2 & G3 \\
\hline \hline 300 & 0.016 & 0.013 & 0.005 \\
\hline 500 & 0.018 & 0.017 & 0.016 \\
\hline 600 & 0.042 & 0.040 & 0.021 \\
\hline 800 & 0.044 & 0.045 & 0.024 \\
\hline 1000 & 0.048 & 0.045 & 0.027 \\
\hline
\end{tabular}

It is generally considered that there are three types of water exist in the hardened geopolymer products: physically bonded water, chemically bonded water and hydroxyl groups $\mathrm{OH}$. The physical bonded water and chemically bonded water evaporate between $20^{\circ} \mathrm{C}$ to $100{ }^{\circ} \mathrm{C}$, and between $100^{\circ} \mathrm{C}$ to $300^{\circ} \mathrm{C}$, respectively.

When the temperature reaches above $300^{\circ} \mathrm{C}$, the dehydroxylation of $\mathrm{OH}$ groups happens with the subsequent polycondensation into siloxo bond $\mathrm{Si}-\mathrm{O}-\mathrm{Si}$, linking neighboring geopolymeric micelles. It is proven that more than $70 \%$ of the reactions water is physically bonded water, which evaporates below $100{ }^{\circ} \mathrm{C}$ without causing any internal stress and remarkable shrinkage. 


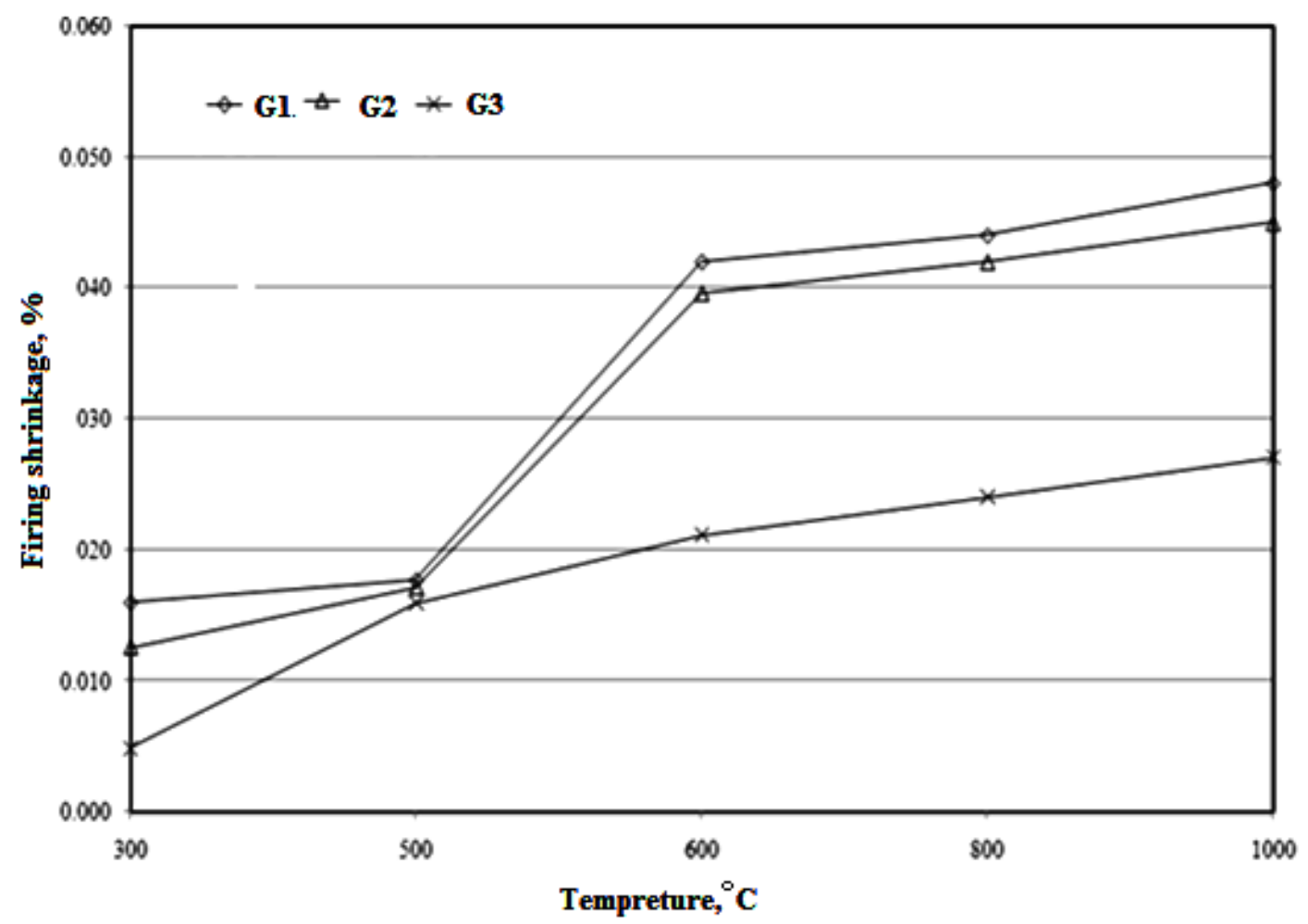

Fig. 2. Firing shrinkage of dried geopolymer specimens of various compositions exposed to 300, 500, 600, 800 and $1000^{\circ} \mathrm{C}$.

However, many micro pores will be produced owing to the empty space left by the water evaporation. The remaining 30\% water, chemically bonded water and hydroxyl groups $\mathrm{OH}$, accounting for up to $90 \%$ of the total shrinkage when the samples are heated from $20{ }^{\circ} \mathrm{C}$ to 500 ${ }^{\circ} \mathrm{C}$ (Perera et al., 2007). Above $500{ }^{\circ} \mathrm{C}$ further shrinkage takes place due to densification and/or volume changes as a result of crystallization and subsequent melting. Davidovits estimated that the evaporation of the free water is not the cause of the damaging stresses except a very small shrinkage, although the free water contributes about $60 \%$ of the total water content in the geopolymer structure (Davidovits, 1988).

However, the remaining $40 \%$ of the water content evaporation is contributing about $90 \%$ of the total shrinkage at high temperatures. The main reason for the shrinkage when the samples are exposed to the $500{ }^{\circ} \mathrm{C}$ may be caused by the loss of the chemically bonded water and hydroxyl groups $\mathrm{OH}$. It can be noticed from the pattern all mixes possess shrinkage values lower than 0.02 $\%$ for temperature lower than $600^{\circ} \mathrm{C}$, also increase replacement of slag by kaolin results in the increase of shrinkage values due to the low reactivity of kaolin leading to the increase of physical water content. We can also notice that mix without kaolin has the lowest values of shrinkage due to the formation of dense structure that hinder the evaporation of water by all its type.

\subsection{Thermo-gravimetric (TGA) analyses}

Thermograms of geopolymer specimens at firing temperatures $\left(0{ }^{\circ} \mathrm{C}, 500{ }^{\circ} \mathrm{C}\right.$ and $\left.1000{ }^{\circ} \mathrm{C}\right)$ are illustrated in Fig. (3). Comparing the TGA patterns with firing temperatures, the geopolymer specimens (G1) gave a total weight loss of $13.91 \%, 7.20 \%$ and $1.10 \%$ at $0{ }^{\circ} \mathrm{C}, 500{ }^{\circ} \mathrm{C}$ and 1000 ${ }^{\circ} \mathrm{C}$, respectively. Also, geopolymer specimens (G2) gave a total weight loss of $11.19 \%, 5.32 \%$ and $0.34 \%$ at $0{ }^{\circ} \mathrm{C}, 500{ }^{\circ} \mathrm{C}$ and $1000{ }^{\circ} \mathrm{C}$, respectively. It is noticeable the geopolymer specimens (G3) gave a good stability and a lower weight loss of $11.68 \%, 3.30 \%$ and $0.81 \%$ at $0{ }^{\circ} \mathrm{C}, 500{ }^{\circ} \mathrm{C}$ and $1000^{\circ} \mathrm{C}$ respectively, as compared with G1 and G2 because of the lower intensity of the formed zeolite structure. 

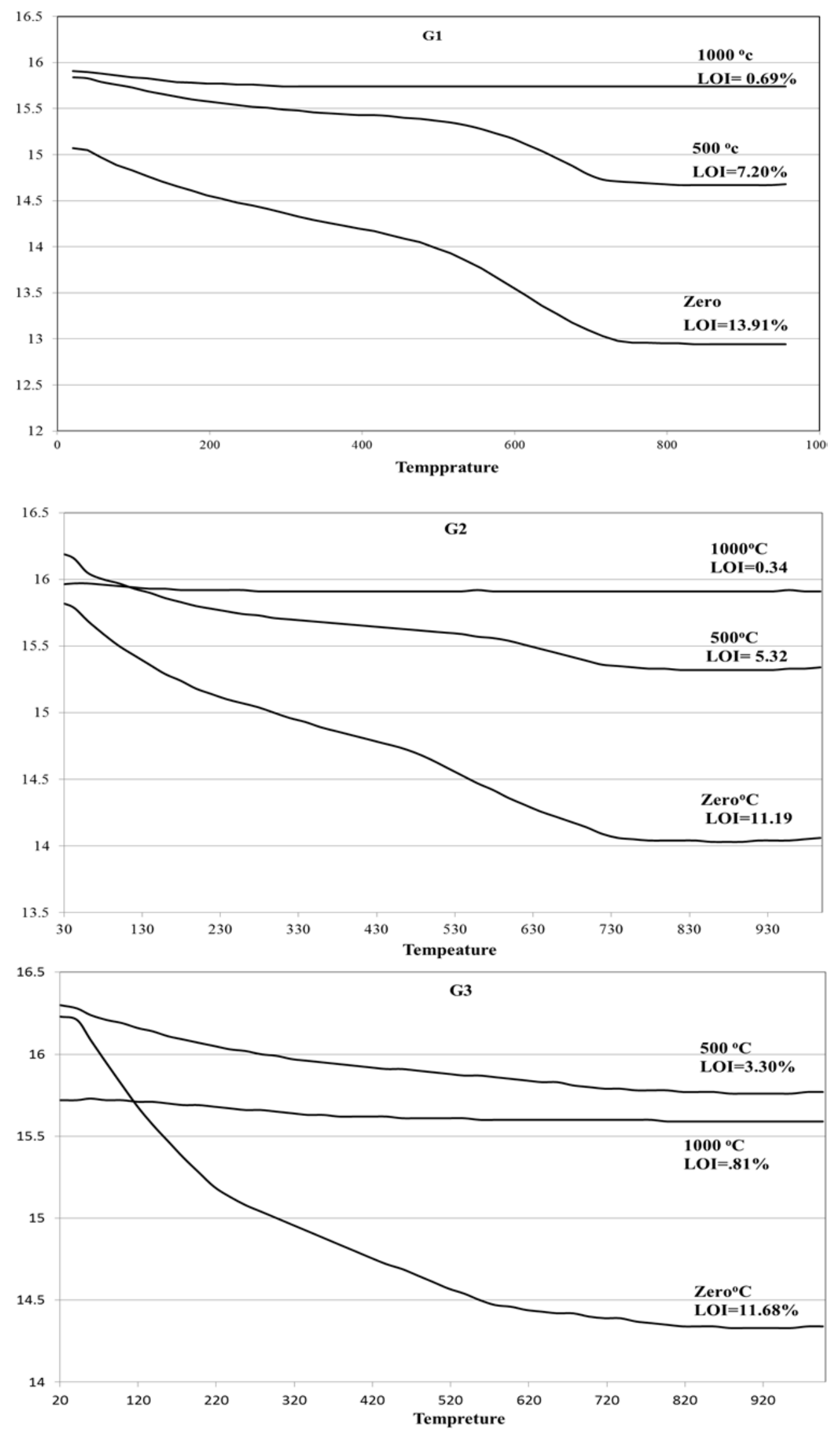

Fig. 3. Thermo-gravimetric graphs of geopolymer specimens of mixes G1, G2 and G3 fired at $0{ }^{\circ} \mathrm{C}, 500{ }^{\circ} \mathrm{C}$ and $1000{ }^{\circ} \mathrm{C}$. 


\subsection{Scanning Electron Microscope}

From previous works a possible explanation for geopolymer shrinkage and cracking is the generation of high capillary pressures between wet and dry areas of the micro pore network, which has been reported to initiate crack propagation in the microstructure. Attempts to avoid shrinkage and crack propagation have focused on modifying the pore structure to minimize capillary porosity, and controlling water loss during curing (Perera et al., 2007; Bell \& Kriven, 2008).

The SEM micrographs geopolymer composite fired at $1000^{\circ} \mathrm{C}$ and having various ratios of kaolin are represented in Fig (4), where as elucidated before from shrinkage data, the mix specimen which has high ratio of kaolin exposed to high deterioration as the lower reactivity of kaolinite material facilitate the evaporation of water and so increase the gaps and cracking between interacting particles Fig (4a).

On lowering the kaolin content to $20 \%$ results in somehow lower cracking depth as well as cohesion between geopolymer ingredient further increases in slag content G3 leads to extra enhancement and stability of the matrix against high temperatures leading to formation of dense structure where formed calcium silicate hydrate leads to formation of matrix free of wide cracks but only some micro cracks formed.


Fig. 4. SEM micrographs of geopolymer specimens after exposure to $1000{ }^{\circ} \mathrm{C}$. 


\subsection{Compressive strength}

Compressive strength of geopolymer specimens was increased with increasing firing temperature up to $500{ }^{\circ} \mathrm{C}$. Generally, this increasing is mainly related to the hydrothermal reaction and inter-autoclaving effect. The increase in strength is noticeable dramatically at 500 ${ }^{\circ} \mathrm{C}$ in both G2 (composed of $80 \%$ water cooled slag and 20\% kaolin) and G3 (composed only of water cooled slag) as shown in Fig. 5.

The data presented in Fig. (2) very closely reflect the trends in Fig. (5), implying a strong correlation between firing shrinkage and changes in mechanical properties, so the firing shrinkage increase slowly up to $500{ }^{\circ} \mathrm{C}$ in the most specimens. On the other hand the compressive strength increase up to $500{ }^{\circ} \mathrm{C}$, due to the microstructure is partially resisting further shrinkage. Explanation for these observations is that the shrinkage mechanism causes a uniform physical contraction in the gel microstructure which, brings about an increase in strength (Kuenzel et al., 2012).

This result related to the increase of vitreous component in water cooled slag which enhance the geopolymer activation and so increase the yield of the reaction product. Moreover, using 50\% kaolin along with water cooled slag (G1) gave a higher fire shrinkage and low thermal stability as compared with other geopolymer specimens. However, the viscous sintering process occurred in the geopolymer matrix at the temperature range from $800{ }^{\circ} \mathrm{C}$ to $1000{ }^{\circ} \mathrm{C}$ led to strength gain (Tai Tran-Thanh et al., 2016) especially in specimen G3.

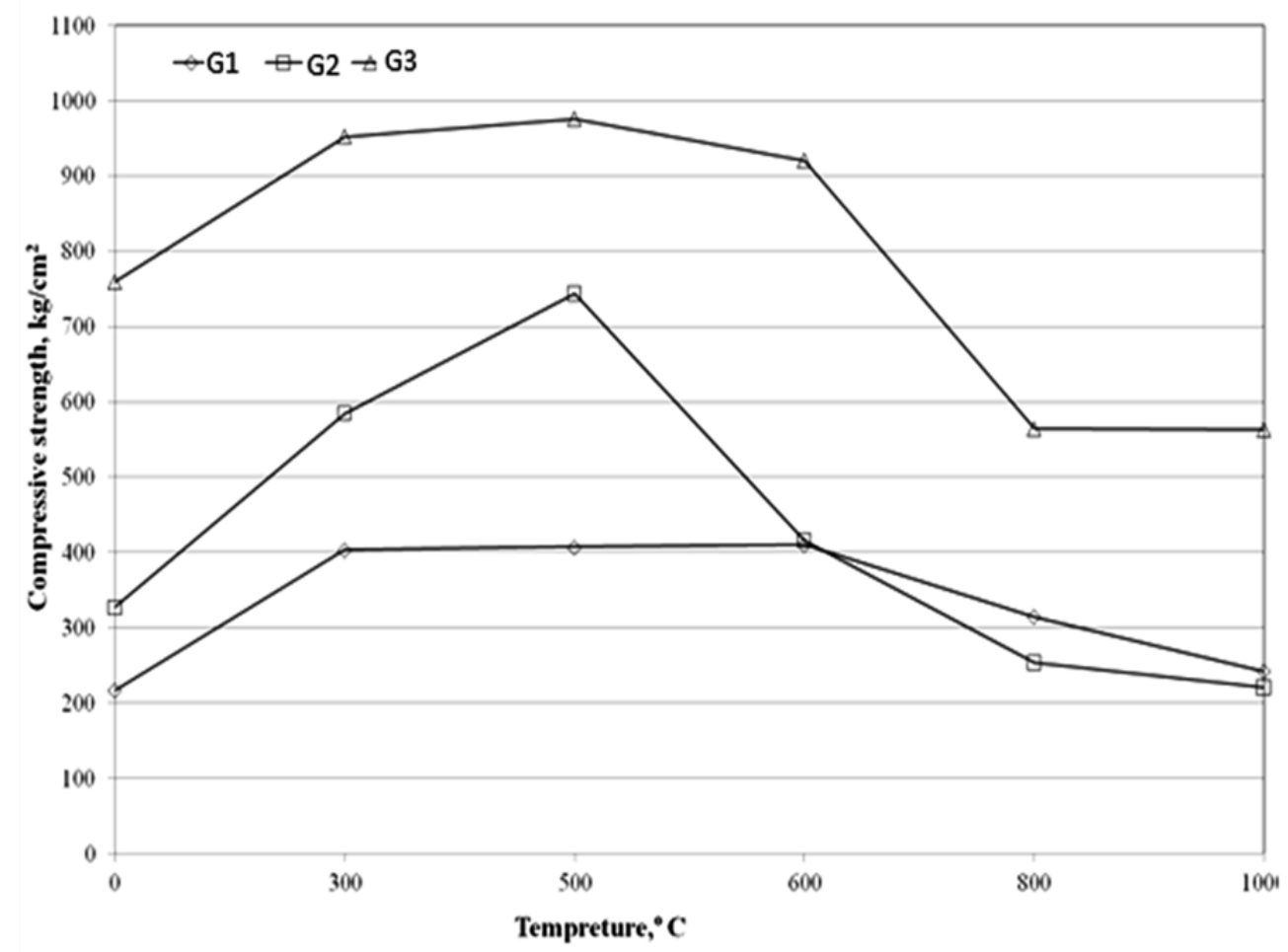

Fig. 5. Compressive strength of geopolymer specimens (G1, G2, G3) after exposure to $0^{\circ}, \mathbf{3 0 0}^{\circ}, \mathbf{5 0 0}^{\circ}, \mathbf{6 0 0}^{\circ}, \mathbf{8 0 0}^{\circ}$ and $1000{ }^{\circ} \mathrm{C}$.

On the other hand, all specimens have promising mechanical properties up to $500^{\circ} \mathrm{C}$, which may be attributed to the effect of nano metakaolin filling the voids, producing denser geopolymer, and/or it may be attributed to the fact that the nano-composite specimens had higher amounts of geopolymer gel and amorphous content. 


\section{Conclusion}

1- The firing shrinkage increases of the geopolymer specimens after exposed to temperatures higher than $300^{\circ} \mathrm{C}$ and up to $1000^{\circ} \mathrm{C}$.

2- The firing shrinkage increase slowly up to $500{ }^{\circ} \mathrm{C}$ in the most geopolymer specimens, and possess lowest values for mixes without kaolin leading to the formation of dense compacted geopolymer.

3- The micrographs showed the increasing of the voids content as well as wide micro cracks within in the paste microstructure with decreasing in slag content, while mix without kaolin has highest cohesive and denser structure at $1000{ }^{\circ} \mathrm{C}$.

4- Compressive strength of geopolymer specimens increased with increasing firing temperature up to $500 \mathrm{oC}$, then strength decrease up to $1000^{\circ} \mathrm{C}$.

5- The studied geopolymer mixes with their highly thermal stability favors their applications in construction sectors.

\section{References}

Abdulkareem, A. O., Al Bakri Abdullah, M. M., Kamarudin, H., \& Khairul Nizar, I. (2013). Alteration in the microstructure of fly ash geopolymers upon exposure to elevated temperatures. In Advanced Materials Research (Vol. 795, pp. 201-205). Trans Tech Publications.

ASTM C109. (2012). "Standard test method for compressive strength of Hydraulic Cement Mortars".

Bakharev, T. (2006). Thermal behaviour of geopolymers prepared using class F fly ash and elevated temperature curing. Cement and Concrete Research, 36(6), 1134-1147.

Barbosa, V. F., \& MacKenzie, K. J. (2003-a). Synthesis and thermal behaviour of potassium sialate geopolymers. Materials Letters, 57(9-10), 1477-1482.

Barbosa, V. F., \& MacKenzie, K. J. (2003-b). Thermal behaviour of inorganic geopolymers and composites derived from sodium polysialate. Materials research bulletin, 38(2), 319-331.

Bell, J.L. \& Kriven, W.M.. (2008). Preparations of ceramic foams from metakaolin-based geopolymer gels. In: Developments in Strategic Materials, Ceramic Engineering and Science Proceedings.

Davidovits, J. (1988). Geopolymer chemistry and properties. Geopolymer 88, First European Conference on Soft Mineralurgy, Compiegne, France, 1, 25-48.

Davidovits, J. (1999). Chemistry of geopolymeric systems. In: Terminology. Geopolymer'99 Second International Conference, Saint-Quentin, France, 9-39.

Duxson, P. S. W. M., Mallicoat, S. W., Lukey, G. C., Kriven, W. M., \& van Deventer, J. S. (2007). The effect of alkali and $\mathrm{Si} / \mathrm{Al}$ ratio on the development of mechanical properties of metakaolin-based geopolymers. Colloids and Surfaces A: Physicochemical and Engineering Aspects, 292(1), 8-20.

Duxson, P., Provis, J. L., Lukey, G. C., Mallicoat, S. W., Kriven, W. M., \& Van Deventer, J. S. (2005). Understanding the relationship between geopolymer composition, microstructure and mechanical properties. Colloids and Surfaces A: Physicochemical and Engineering Aspects, 269(1-3), 47-58.

El Nagar, A. M. (2016). Applied geological studies on some kaolin deposits and industrial wastes for production of nano geopolymer composites, Egypt. Ph D., Al Azhar University, Faculty of Science, May.

Kong, D. L., \& Sanjayan, J. G. (2008). Damage behavior of geopolymer composites exposed to elevated temperatures. Cement and Concrete Composites, 30(10), 986-991.

Kong, D. L., \& Sanjayan, J. G. (2010). Effect of elevated temperatures on geopolymer paste, mortar and concrete. Cement and concrete research, 40(2), 334-339. 
Kuenzel, C., Vandeperre, L. J., Donatello, S., Boccaccini, A. R., \& Cheeseman, C. (2012). Ambient temperature drying shrinkage and cracking in metakaolin-based geopolymers. Journal of the American Ceramic Society, 95(10), 3270-3277.

Messina, Ferone, Colangelo, Roviello, \& Cioffi. (2018). Alkali activated waste fly ash as sustainable composite: Influence of curing and pozzolanic admixtures on the early-age physico-mechanical properties and residual strength after exposure at elevated temperature. Composites Part BEngineering, 132, 161-169.

Norsker, H. (1987). The Self-reliant potter: refractories and kilns, Friedr. Braunschweig/Wiesbaden: Vieweg \& Sohn.

Palomo, A., Blanco-Varela, M. T., Granizo, M. L., Puertas, F., Vazquez, T., \& Grutzeck, M. W. (1999). Chemical stability of cementitious materials based on metakaolin. Cement and Concrete Research, 29(7), 997-1004.

Perera, D. S., Uchida, O., Vance, E. R., \& Finnie, K. S. (2007). Influence of curing schedule on the integrity of geopolymers. Journal of materials science, 42(9), 3099-3106.

Provis, J. L., Yong, C. Z., Duxson, P., \& van Deventer, J. S. (2009). Correlating mechanical and thermal properties of sodium silicate-fly ash geopolymers. Colloids and Surfaces A: Physicochemical and Engineering Aspects, 336(1-3), 57-63..

Rahier, B. (1996). van Mele, and J. Wastiels,"Low-Temperature Synthesized Aluminosilicate Glasses Part II Rheological Transformations During low-Temperature Cure and High-Temperature Properties of a Mode/Compound,". J. Mater. Sci, 31(1), 80-85.

Rickard, W. D., Riessen, A. V., \& Walls, P. (2010). Thermal character of geopolymers synthesized from class $\mathrm{F}$ fly ash containing high concentrations of iron and $\alpha$-quartz. International Journal of Applied Ceramic Technology, 7(1), 81-88.

Rickard, W. D., Temuujin, J., \& van Riessen, A. (2012). Thermal analysis of geopolymer pastes synthesised from five fly ashes of variable composition. Journal of non-crystalline solids, 358(15), 1830-1839.

Shaikh, F., \& Haque, S. (2018). Effect of nano silica and fine silica sand on compressive strength of sodium and potassium activators synthesised fly ash geopolymer at elevated temperatures. Fire and Materials, 42(3), 324-335.

Tai Tran-Thanh. Tuan Le-Anh. Kwon Hyug Moon. (2016). Alteration in the Mechanical Strength of Fly Ash Based Geopolymer Mortar upon Exposure to Elevated Temperatures. International Journal of Applied Engineering Research, V. 11, 21, p. 10433-10440. 